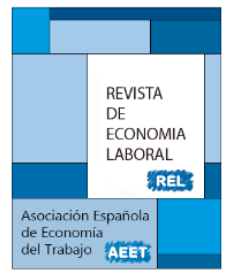

\title{
NUEVAS FUNCIONES DE LA NEGOCIACIÓN COLECTIVA Y ALTERACIÓN DE SU MARCO NORMATIVO ${ }^{1}$
}

\author{
Jesús Cruz Villalón \\ Universidad de Sevilla
}

Recibido Septiembre 2016; Aceptado Noviembre 2016

\section{Resumen}

La negociación colectiva en su origen en la sociedad industrial desplegaba dos funciones relativamente simples y complementaria: de un lado se presentaba como instrumento de tutela incrementada de los derechos de los trabajadores más allá de los previstos por parte de la normativa estatal, al mismo tiempo que tendía a establecer un régimen homogéneo de condiciones de trabajo en la empresa y/o el sector productivo con vistas a evitar escenarios de competencia desleal por la vía del dumping social.

Sin llegar a desaparecer las anteriores funciones, la normativa laboral y la propio desarrollo del modelo económico le viene exigiendo a la negociación colectiva la asunción de nuevas y decisivas funciones: adaptación a las peculiaridades empresariales y sectoriales para dar respuestas a los singulares requerimientos de las partes en el ámbito local, adaptación de las condiciones de trabajo al cambio del ciclo económico o de la coyuntura empresarial, distribución equitativa de sacrificios entre los diferentes grupos de trabajadores, la gestión de la segmentación laboral provocada con naturalidad por el mercado, asi como propiciar la flexibilidad laboral en un escenario de competitividad globalizada.

La capacidad de asumir todas estas funciones por parte de la negociación colectiva es el gran reto que se le presenta en el escenario actual, bajo el riesgo de perder de lo contrario capacidad de protagonismo y de centralidad en el gobierno del sistema de relaciones laborales

Palabras clave: Derecho del Trabajo, Negociación Colectiva, Mercado de Trabajo Clasificación JEL: K31, J53

${ }^{1}$ El presente estudio tiene su origen en el trabajo elaborado para el libro en recuerdo del profesor Manuel Ramón Alarcón Caracuel, AA. VV., Los grandes debates actuales en el Derecho del Trabajo y la protección social, Consejo Andaluz de Relaciones Laborales, Sevilla 2016. Este trabajo se ha realizado en el marco del proyecto de investigación "Técnicas jurídicas y efectividad de la norma laboral en la gestión del cambio", Ministerio de Economía y Competitividad (DER2014-52549-C4-1-R).

(C) Revista de Economía Laboral 


\begin{abstract}
Collective bargaining at its origin in the industrial society had two relatively simple and complementary functions: on the one hand, it presented itself as an instrument for the increased protection of workers' rights, beyond those provided for by state legislation, at the same time as tended to establish a homogeneous regime of working conditions in the enterprise and / or the productive sector in order to avoid scenarios of unfair competition through social dumping.

Notwithstanding the previous functions, labor regulations and the development of the economic model itself require collective bargaining to take on new and decisive functions: adaptation to the peculiarities of business and industry to respond to the unique requirements of the parties at the local level, adapting working conditions to changing the economic cycle or the business climate, equitable distribution of sacrifices among different groups of workers, management of labor market segmentation, as well as facilitating the flexibility in a scenario of globalized competitiveness.

The capacity to assume all these functions by collective bargaining is the great challenge that is presented to us in the current scenario, under the risk of losing the capacity of protagonism and centrality in the government of the industrial relations system

Key words: Labour Law, Collective Bargainig, Labour Market

JEL Classification: K31, J53
\end{abstract}




\section{La función originaria de tutela laboral: irrenunciabilidad y suplementariedad}

Las perceptibles importantes transformaciones que se vienen produciendo, desde hace ya bastante tiempo, en el funcionamiento de la economía de los países desarrollados, debidas al profundo proceso de la globalización, están influyendo decididamente sobre las funciones encomendadas a la negociación colectiva, lo que, a su vez, acaba provocando importantes cambios en la forma de establecerse las relaciones entre la norma estatal y los convenios colectivos. Como diría Giugni, cualquier doctrina relativa al convenio colectivo nunca resulta definitiva, justamente porque la realidad sobre la que actúa se encuentra en continuo movimiento, y cualquier construcción sólo es idónea para un momento evolutivo del mismo.

Entendemos a estos efectos por función de la negociación colectiva, como institución jurídica, los fines $u$ objetivos que el ordenamiento jurídico pretende con su reconocimiento, garantía y fomento. O bien, visto desde otra perspectiva, la relativa a su eficacia, por tanto, con independencia de la pretendida la voluntad del legislador, cuál es en concreto el cometido desempeñado por la negociación colectiva sobre las relaciones laborales y el mercado de trabajo.

En sus orígenes, la negociación colectiva se concibió exclusivamente como un instrumento de reforzamiento de la defensa de los intereses de los trabajadores, para superar el marcado desequilibrio de fuerzas entre las partes a nivel individual, como un instrumento de compensación de la desigualdad de arranque existente entre las partes. De este modo, la negociación colectiva cumplía una estricta función de tutela de la posición jurídica de los trabajadores en el ámbito de las relaciones laborales. Hay modelos donde tal función de tutela se le atribuye en exclusiva o primordialmente al convenio colectivo, pero hay otros ordenamientos jurídicos donde la normativa laboral estatal desempeña también ese cometido de establecimiento de un régimen de tutela del trabajador, si bien cuando ello sucede no se verifica por la vía de excluir la intervención de la negociación colectiva; en esos otros ordenamientos jurídicos la función tutelar se asume de manera conjunta por parte tanto de la norma estatal como del convenio colectivo, de modo que ambas fuentes se complementan y refuerzan mutuamente en tal finalidad de protección de las condiciones laborales de los trabajadores.

Naturalmente, sin olvidar tampoco que, como contrapunto a ello, la negociación colectiva se articula como una institución orientada a la consecución de una paz laboral entre las partes durante el período de su 
vigencia, en la medida en que constituye un instrumento a través del cual se logra un equilibrio de intereses entre las partes, que desemboca en ese compromiso de paz social; compromiso que puede ser tácito o expreso, que puede en algunos ordenamiento ser impuesto legalmente (art. 11.c Real Decreto Ley de Relaciones de Trabajo de 4 de marzo de 1977, en adelante RDLRT), o bien de posible ampliación vía pacto entre las partes (art. 8.1 RDLRT y art. 82.2 ET). La función unitaria de la negociación colectiva es la de ser un instrumento para la composición tendencialmente equilibrada del conflicto entre trabajadores y empresarios. Por ello, tendrá también esa lectura del convenio como instrumento de equilibrio de intereses entre unos y otros.

Esa función tutelar de la norma laboral, en concreto del convenio colectivo, especialmente dentro de la cultura anglosajona, se puede lograr por la vía de los hechos, de modo que socialmente se consideraría inconcebible el incumplimiento de lo pactado por sindicatos y empresarios a través del mismo; como acuerdo "entre caballeros" (gentlemen's agreement) debe ser cumplido.

Ahora bien, en otras culturas jurídicas, más propias del ordenamiento europeo continental, esa función tutelar del convenio colectivo se diseña desde una perspectiva institucional con precisas reglas jurídicas. Como diría Vardaro, la configuración del convenio colectivo como contrato de derecho privado permite al Estado desarrollar la misma función de intervención legislativa que lleva a cabo respecto del resto de los contratos regulados en el Código Civil, situándose el Estado en una posición externa a los intereses de las partes y, como tal, super partes y con una posición esencialmente arbitral. Eso sí, manifestándose inmediatamente que resulta insuficiente una intervención legal idéntica a la propia del resto de la contratación civil, requiriéndose de una regulación propia y diferenciada del convenio colectivo, con vistas a otorgar material eficacia a las funciones que determinan el surgimiento de la negociación colectiva como fenómeno social. Eso da lugar, precisamente a que, aunque el convenio colectivo surja como una manifestación del contrato privado, la configuración jurídica del mismo no se adapte a los requerimientos del convenio como institución y que su función sólo pueda lograrse sobre la base de una concepción propia del mismo, que ni puede comprenderse plenamente a la luz de la teoría de los contratos ni tampoco pueda entenderse plenamente por vía de su total asimilación a la norma jurídica estatal. El convenio colectivo posee su propia identidad social, con una funcionalidad propia que, a resultas de ello, requiere de un tratamiento jurídico 'ad hoc' y diferenciado de otras instituciones jurídicas de las que tampoco puede negar su origen. En estas otras culturas, desde la perspectiva técnico-jurídica, la 
institución que en primera instancia ha garantizado desde sus orígenes remotos la función tutelar es la consideración de la norma laboral, tanto la estatal como la pactada, como regla imperativa desde el punto de vista del trabajador, en la singular lectura de que éste no puede renunciar a los estándares laborales reconocidos por la norma legal y convencional: "los trabajadores no podrán...disponer válidamente de los derechos reconocidos como indisponibles por convenio colectivo" (art. 3.5 Estatuto de los Trabajadores, en adelante ET).

En particular, en aquellos países en los que la normativa laboral estatal desempeña también una función tutelar, su despliegue conjunto con la paralela actuación de la negociación colectiva en la misma clave se articula por la vía de entender que el convenio colectivo puede mejorar desde el punto de vista del interés del trabajador los estándares laborales legales, pero tiene vedado reducirlos o disminuirlos. De este modo, junto al precedente principio de irrenunciabilidad (estrechamente vinculado al reconocimiento constitucional de la fuerza vinculante de los convenios colectivos, conforme a al art. 37.1 CE) ha establecido desde los orígenes del modelo legal una relación de "suplementariedad" entre norma estatal y convenio colectivo, de modo que éste puede establecer las condiciones laborales más favorables para los intereses de los trabajadores que considere oportuna "dentro del respeto a las leyes" (art. 85.1 ET); o bien, dicho lo mismo de otro modo, con el condicionante de "que deberán respetar en todo caso los mínimos de derecho necesario" establecidos legalmente (art. 3.3 ET). Desde esa óptica, la negociación colectiva se presentaba exclusivamente como la vía de mejora de las condiciones laborales desde el punto de vista de los trabajadores respecto de los estándares de obligado respeto contemplados en la normativa estatal.

En esa lógica de la función de tutela del trabajador, en los países de la Europa continental, donde en paralelo emerge también un claro intervencionismo de lo público en la fijación de condiciones de trabajo, la relación típica entre ley y convenio colectivo responde al modelo más clásico de la suplementariedad o normas de derecho necesario relativo que introducen mínimos imperativos desde el punto de vista de la tutela de los intereses de los trabajadores: la norma estatal fija condiciones de trabajo que actúan como el umbral inferior que en todo caso puede ser superado por parte del convenio colectivo desde la perspectiva de los intereses de los trabajadores; la norma estatal se convierte en indisponible para la negociación colectiva en cuanto que mínimo de obligado respeto, pero abre paso en todo caso a su alteración en la medida en que incorpore reglas de superior tutela en beneficio del trabajador. Regla fácilmente articulable cuando lo regulado en la norma legal tiene un carácter cuantitativo: incremento de la cuantía retributiva, reducción 
de la duración de la jornada laboral, etc.

\section{La contención del "dumping social" como adicional función originaria}

Apenas que la negociación colectiva se va desarrollando y consolidando en la sociedad industrial, con el paso del tiempo y en paralelo la misma pasará a cumplir una función adicional, en modo alguna opuesta a la precedente sino todo lo contrario reforzadora de la misma, consistente en evitar que la concurrencia empresarial se despliegue sobre la base de desigualdades de costes laborales. Desde este punto de vista se pretenderá que, como función añadida, la negociación colectiva conjure los riesgos de que la competencia mercantil provoque efectos de "dumping social". Desde esta perspectiva se intentará que la competencia entre empresas se base en otros elementos, como serían los relativos a la productividad, el desarrollo tecnológico, la mayor calidad de los productos y servicios ofrecidos, pero garantizando que a igualdad de trabajo no se produzcan diferencias de costes laborales entre unas y otras empresas.

A los efectos de lograr que la negociación colectiva cumpla esta nueva función la clave se encuentra en que la misma supere el ámbito empresarial, para asentarse creando un ámbito de aplicación multiempresarial a través de la conformación en ciertos modelos nacionales de una estructura de negociación a nivel sectorial, con tendencia aplicativa a conjunto de las empresas del sector e impidiendo con ello que específicas empresas escapen al cumplimiento de los estándares laborales mínimos establecidos por el convenio sectorial.

De nuevo, una vez más, en ciertas culturas de impronta anglosajona ese resultado se logra esencialmente por la vía de los hechos, de la imposición de las condiciones laborales previstas en los convenios colectivos al conjunto de las empresas, dando por inconcebible su transgresión con el efecto derivado de provocar un resultado de "dumping social".

En definitiva, como dirá Valdés Dal-Ré, del lado de los trabajadores, esta función ha erigido a la negociación colectiva en el instrumento principal de ordenación del mercado de trabajo, logrando la mejora de sus condiciones de trabajo y, con ello, el progreso y cohesión sociales. Y, del lado de los empresarios, ha contribuido de una manera eficaz y transparente a asegurar una concurrencia leal entre las empresas, desplazando la mejora de la competitividad hacia campos distintos de los laborales, como pueden ser, a título de ejemplo, la 
formación, la inversión, la innovación o la eficiencia en el servicio.

Con esa conjunción de funciones -tutelar, de equilibrio de intereses, logro de la paz social y ordenación de la concurrencia mercantil- la negociación colectiva alcanza un protagonismo central en el desarrollo de las relaciones laborales, que desemboca en una funcionalidad más amplia en la perspectiva del desarrollo del sistema político, en la medida en que la institución asume un rol final de gobierno de las relaciones laborales.

En paralelo, en otras culturas jurídicas, dicha funcionalidad se garantiza por el establecimiento de reglas precisas de efectividad de la norma convencional. La primera de ellas, en negativo, será la de entender que la negociación colectiva se asienta en el ordenamiento jurídico como una institución a la que se reconoce su eficacia jurídica vinculante, aun cuando la misma materialmente produzca un efecto de alteración de las reglas del mercado, por cuanto que por su propia naturaleza el convenio colectivo actúa como instrumento limitativo de la competencia mercantil. Precisamente por ello, la jurisprudencia de la Unión Europea tendrá que partir de esta premisa para aceptar la virtualidad de la negociación colectiva en el tráfico económico (por todas, STJUE 21 de septiembre de 1999, asunto Albany, C-67/96), del mismo modo que se mostrará especialmente reticente, cautelosa o limitativa de los fenómenos de negociación colectiva que se producen entre los trabajadores autónomos como titulares de actividades empresariales y sus empresas clientes (por todas, STJUE 4 de diciembre de 2014, asunto FNV Kunsten Informatie en Media, C-413/13).

Visto desde la perspectiva afirmativa, esa funcionalidad de la negociación colectiva requerirá de un diseño jurídico del convenio colectivo, sobre diversas reglas, entre las que destacará la eficacia 'erga omnes' del convenio colectivo desde la perspectiva sobre todo de su aplicación general al total de las empresas incluidas dentro del ámbito de aplicación del convenio colectivo, así como de una concepción de que el convenio colectivo de empresa debe respetar como mínimos los estándares laborales pactados en el convenio sectorial. Respecto de la eficacia 'erga omnes' conviene recordar que es una fórmula que por diferentes vías -legal, administrativa o judicial-acaba funcionando en la práctica totalidad de los países de la Europa continental, no pudiéndose considerar que a estos efectos España sea una situación excepcional ni mucho menos en ese contexto continental; el contraste lo es en exclusiva respecto de los países de impronta anglosajona.

Por lo demás, desde el punto de vista de la relación de la negociación colectiva con la norma estatal, ello no requiere cambio alguno en la técnica jurídica de relación entre ley y convenio colectivo, cuando 
menos por lo que afecta al alcance regulativo de las condiciones de trabajo: la relación de suplementariedad es igualmente adecuada para tal objetivo. La clave para el logro de esta función adicional se sitúa en el terreno de la estructura de la negociación colectiva (permitiendo la conformación del ámbito sectorial con primacía al empresarial) y en la eficacia del convenio colectivo (vinculante para los trabajadores y empresarios incluidos dentro de su ámbito de aplicación). Insistimos, lo importante desde la perspectiva que estamos analizando aquí, será que esta segunda función no comportará alteración, corrección o matización de las técnicas de relación más clásicas entre ley y convenio colectivo, basadas en la suplementariedad o norma mínima.

\section{Funciones de diversificación normativa y técnica de complementariedad}

También desde sus orígenes nuestros modelos clásicos de negociación colectiva se convertirán en un útil instrumento de respuesta a los requerimientos de diversificación normativa que van surgiendo en el seno del mercado de trabajo, apenas que el Derecho del Trabajo experimenta una fuerte tendencia hacia la expansión subjetiva pretendiendo aplicar todas sus normas al conjunto de la población asalariada, al mismo tiempo que el desarrollo económico comienza a mostrar multitud de singularidades en las relaciones laborales de cada uno de los sectores y actividades productivas. Apenas que la legislación laboral estatal pretenda ser de aplicación al conjunto del mercado de trabajo, se advierte la enorme dificultad de establecer reglas precisas y comunes de aplicación universal al total de la población asalariada. La falta de homogeneidad de la actividad económica (bien lo sea por razón del sector productivo, bien lo sea por razón del territorio o bien lo sea por motivo de la concreta actividad profesional que se ejecuta, sin olvidar tampoco a veces la diversidad de situaciones contrastadas entre grandes y pequeñas empresas) muestra inmediatamente cómo las reglas uniformes para todos los empleadores y trabajadores sólo se pueden establecer desde la norma estatal para determinadas instituciones marco de las relaciones laborales, pero que otras materias requieren de notables especialidades por razón de la profesión, del sector productivo o del territorio, conforme a un modelo clásico que se ha conocido como de diversificación normativa.

De este modo, la diversificación normativa puede aparecer en algunos sistemas perfectamente atendida por parte de la negociación colectiva, en la medida en que una estructura de cierta pluralidad como 
suele ser lo habitual en un mapa complejo de la negociación colectiva permite el establecimiento de reglas idóneas y más detalladas por razón del sector, el territorio o la profesión. En ello influye la evolución de la unidad de negociación colectiva típica del convenio, en sus orígenes centrada en el oficio, sucesivamente en la empresa y posteriormente en el sector económico, para, en tiempos más recientes, ser el resultado de una ordenación compleja y articulada que pretende con mayor o menor éxito según los modelos atender a las diversas variantes de especialidad del mercado de trabajo.

Ciertamente, en algunas ocasiones la propia norma estatal, a través de diversas especialidades, puede llegar también a atender a esa función de diversificación normativa, bien lo sea por la vía de la conformación de relaciones laborales especiales, pluralidad de modalidades contractuales o bien regímenes particulares de jornadas especiales. Pero ello difícilmente se puede llevar a cabo de manera plena de no acudirse a un sistema más capilarizado y reticular de legislación estatal extensiva; como sucedió en algún tiempo en nuestro ordenamiento franquista a través de las Ordenanzas Laborales y Reglamentaciones de Trabajo, si bien no es casual que esa fórmula se entendiese como suplantadora del sistema natural de la negociación colectiva $\mathrm{y}$, por ende, contrario a la lógica del reconocimiento constitucional de la autonomía colectiva.

Por ello, lo habitual es que apenas emergen los requerimientos precedentes de diversificación normativa en un mercado de trabajo mínimamente evolucionado, estos sean atendidos también por la negociación colectiva, lo cual afianza notablemente el rol protagonista del convenio colectivo en el correspondiente sistema de relaciones laborales. A estos efectos, el devenir histórico de nuestro modelo ha sido bastante heterodoxo, dado que la agobiante intervención política en todos los ámbitos propia del franquismo, unida a la bien conocida marginación de la autonomía colectiva durante el mismo, condujo, como ya hemos destacado, a una importante centralidad de las Ordenanzas Laborales, que vinieron a ocupar el espacio natural de los convenios y con ello a atender a las exigencias aludidas de diversificación normativa. Eso sí, apenas que nuestro sistema tiende a normalizarse y homologarse en la clave propia de cualquier sistema democrático de relaciones laborales basado en un auténtico reconocimiento de la autonomía colectiva, se verifica el inexorable proceso de desaparición de las Ordenanzas Laborales, con la correlativa asunción del papel propio de regulación especializada por sectores, territorios, empresas y profesiones que le debe corresponder a la negociación colectiva como instrumento de atención a la función de diversificación normativa. 
Contemplada esta nueva función de atención a los requerimientos de la diversificación normativa desde el punto de vista de las técnicas jurídicas de relación entre ley y convenio colectivo, las mismas pueden continuar con lógicas precedentes a las originarias, si acaso enriquecidas por medio de otras técnicas adicionales.

En efecto, desde la perspectiva de esta otra función, no cabe la menor duda de que la fórmula de la suplementariedad ya mencionada puede atender perfectamente a las exigencias de la diversificación normativa. La fórmula del estándar común a toda la población asalariada por medio de la normativa estatal, vía norma mínima, que sucesivamente viene precisado con reglas de mayor intensidad en la tutela al trabajador en cada sector, territorio, empresa o profesión por parte de la negociación colectiva, puede ofrecer puntual respuesta a los requerimientos propios de la diversificación normativa.

Eso sí, la suplementariedad se mueve esencialmente en el terreno de la fijación cuantitativa de condiciones de trabajo, con menor capacidad de juego cuando nos referimos a reglas de carácter cualitativo. Para este otro terreno, la función de diversificación normativa no se atiende exclusivamente, ni siquiera debidamente, por medio de la suplementariedad. Ello determina la generalización de una nueva técnica de relación entre ley y convenio colectivo, a través de la ya también clásica regla de la complementariedad: la norma estatal establece criterios generales de la institución, que sean referibles al conjunto de los sectores, de las empresas y al total de la población asalariada, que sucesivamente venga perfeccionada, por medio de reglas de desarrollo o concreción por parte de la negociación colectiva. La fórmula es moldeable en términos muy diversos, por cuanto que cabe desde una regulación relativamente precisa por parte de la norma estatal, que deje un juego de complementariedad de carácter eminentemente técnico y poco innovador a la negociación colectiva, hasta una regulación de elevada generalidad a través de simples principios orientadores en la norma estatal, que proporcione un espacio de mayor calado y con intensa capacidad de diversificación regulativa por parte de la negociación colectiva.

En todo caso, desde la perspectiva más significativa en la clave que estamos analizando en estos momentos, con esa nueva incorporación de funciones y esa nueva técnica de relación, la negociación colectiva mantiene su lógica tradicional, esencialmente de tutela de los intereses de los trabajadores, incluso se podría afirmar que la perfecciona logrando dosis superiores de efectividad. Lo decisivo será que ambas técnicas de relación entre Ley y convenio colectivo (suplementariedad y complementariedad), no entran en contradicción, sino que, por el contrario, actúan en planos diversos, se enriquecen mutuamente y se 
refuerzan entre ellas: la norma estatal sigue cumpliendo un papel de fijación de estándares mínimos y la negociación colectiva atiende a su papel diversificación normativa, sin por ello abandonar el precedente de tutela laboral del trabajador $y$ de freno al dumping social interempresarial.

\section{Nuevas funciones en el contexto de una economía abierta y centrada en la concurrencia empresarial}

Las transformaciones tanto de las funciones como de las técnicas de relación son de mayor calado cuando, desde hace ya unas cuantas décadas, se alteran notablemente las economías desarrolladas, evolucionando hacia modelos más abiertos, de plena intensificación de la competitividad empresarial en todos los frentes y, a la postre, en un escenario de plena globalización de la actividad económica. Proceso de globalización que se ve acompañado por la decadencia del modelo fordista de producción, el desplazamiento de la centralidad de la ocupación desde el sector industrial hacia el sector servicios, la extensión de las tecnologías de la información y de las comunicaciones, así como la intensificación de las fórmulas de descentralización productiva en la organización de las empresas; sin olvidar novedades más recientes, pero de intenso calado, como son las derivadas de la introducción del euro como moneda única europea, así como de los imperativos derivados de la nueva gobernanza europea.

Todo ello acaba confluyendo en presiones a favor de reformas laborales más o menos intensas en la generalidad de los países europeos con sistemas laborales de intenso intervencionismo en lo normativo, particularmente incisivas en los países periféricos de la Unión Europea. Tales reformas inicialmente han ido enfocadas hacia cambios en la normativa estatal, pero en poco tiempo también han dado lugar a que el foco de atención se ponga en la negociación colectiva y en las funciones que la misma debe asumir en el nuevo escenario económico.

Todos estos cambios sucesivos y acumulados, que van en progresión tanto por lo que refiere a sus contenidos materiales como a su intensidad, cuando menos hasta la actualidad, no puede decirse que se presenten como una negación o anulación de las funciones más clásicas de la legislación laboral y, en particular, de las funciones precedentes atribuidas a la negociación colectiva. Una lectura de conjunto de la vigente normativa respecto de la mayoría de los ordenamientos laborales de la Europa continental y, por ende, también de España, muestra que la 
normativa laboral se mantiene en gran medida dentro de la lógica de tutela de la posición jurídica del trabajador; siendo referible tal afirmación tanto a la normativa laboral estatal como a la negociación colectiva. Y, como consecuencia de ello, también puede constatarse que la técnica de la suplementariedad en las relaciones entre ley y convenio colectivo pervive en muchas de sus manifestaciones institucionales. En definitiva, a estas alturas puede seguir afirmándose que el principio de norma mínima goza de buena salud entre nosotros. Como diría Alarcón Caracuel, el modelo de relaciones ley-negociación colectiva actualmente vigente en nuestro ordenamiento jurídico responde a un esquema perfectamente clásico: la norma estatal establece condiciones mínimas inderogables «in pejus» que, en cambio, pueden ser mejoradas por la autonomía colectiva; al menos por ahora...el principio de norma mínima goza de buena salud.

Ahora bien, lo anterior no comporta minusvalorar las transformaciones que se han producido y, en particular, quitar importancia al impacto que las mismas están teniendo sobre las funciones de la negociación colectiva, con consecuencias notables sobre las relaciones entre ley y convenio colectivo.

Para captar en toda su trascendencia la evolución funcional y normativa en esta materia, resulta imprescindible enfocar el análisis hacia un arco temporal amplio, de valoración en su conjunto de todo lo acontecido desde la década de los años '80 del siglo pasado hasta el momento presente, no concentrando la mirada exclusivamente en una concreta reforma laboral ni en una específica novedad en la negociación colectiva. Los cambios a estos efectos resultan paulatinos, puede que reducidos como consecuencia de cada concreta reforma legal, pero que produciéndose cada una de ellas en clave aluvional respecto de las precedentes, como acumulación sucesiva de novedades puntuales, acaban dibujando un mapa funcional y normativo cualitativamente diversos. Ese nuevo mapa no llega a suprimir, como ya hemos indicado, las funciones y técnicas normativas más tradicionales, que conviven con las nuevas; pero sí que las corrige, incluso llega a limitarlas en la medida en que deben conciliarse con las nuevas funciones, por lo que el balance general resulta más difícil y complejo de efectuar, pero que, en todo caso, se trata de nuevas funciones y técnicas que, como efecto reflejo, afectan debilitando en parte a las más clásicas.

\subsection{Función adaptativa}

Desde esta perspectiva, conviene recordar someramente cómo paulatinamente la negociación colectiva ha pasado de desplegar una 
función exclusivamente adquisitiva (de reconocimiento de nuevos derechos y garantías a los trabajadores) a cumplir igualmente una misión adaptativa (de acomodación de las condiciones de trabajo a los cambios del ciclo económico general o empresarial particular). Como diría Rivero Lamas, cuando los sindicatos no pueden presionar para la distribución del excedente empresarial porque éste no existe, se les pide que se conviertan en gestores de situaciones de crisis para mantener en el mercado a la empresa y amortiguar los efectos negativos que sobre el empleo proyectan las situaciones económicas adversas, el impacto de las nuevas tecnologías y las reorganizaciones productivas. En esta nueva perspectiva, los contenidos de los convenios no se pueden ya concebir como un simple in crescendo, en clave de irreversibilidad de los estándares alcanzados en un momento dado, sino que pasan a ser en clave de incremento o disminución de intensidad en función de las expectativas económicas de las empresas y de la actividad económica. Ello, sobre todo, se presenta especialmente novedoso en los momentos depresivos, donde las crisis, sean globales o particularizadas, exigen una reducción de la protección o de las garantías, lo sean en los tiempos de trabajo o incluso en los niveles retributivos. No sólo se trata de superar presunciones nunca aseguradas de blindaje de los derechos adquiridos a título individual sino igualmente en lo incorporado a los convenios colectivos, con lo cual se comienza a alterar la función del convenio colectivo que progresivamente pasa a ser más adaptativa que adquisitiva permanente.

La regla general que consagrará esa función adaptativa no será otra que la relativa al principio de modernidad en la sucesión de contenidos derivada de la renovación de los convenios colectivos, recogido expresamente en la normativa española desde la reforma de 1994: "el convenio colectivo que sucede a uno anterior puede disponer sobre los derechos reconocidos en aquél. En dicho supuesto se aplicará íntegramente, lo regulado en el nuevo convenio" (art. 82.4 ET); dicho en otros términos, "el convenio que sucede a uno anterior deroga en su integridad a este último, salvo los aspectos que expresamente se mantengan" (art. 86.4 ET); regla explicitada desde la reforma de 1994, si bien la generalidad de la doctrina lo deducía con anterioridad del juego natural de la sucesión normativa. Esa orientación hacia la función adaptativa se ve reforzada aún más si cabe con las últimas reformas legales, en especial la de 2012, a través del nuevo equilibrio de posiciones que se establece a través del nuevo régimen de pérdida de vigencia de las reglas sobre ultraactividad de los convenios colectivos, donde como resulta fácil imaginar un modelo que facilita en mayor medida la decadencia del convenio colectivo favorece indiscutiblemente la función 
adaptativa del convenio colectivo (art. 86.3 ET).

Más aún, en ocasiones el legislador entiende que esa función adaptativa al cambio del ciclo económico no sólo se debe propiciar en la sucesión temporal del convenio, sino también durante la propia vigencia temporal pactada del mismo convenio. A tal efecto surge y se perfecciona el procedimiento de inaplicación o descuelgue del convenio colectivo, arrancando con la reforma de 1994 pero de forma especialmente incisiva a partir de la reforma de 2012, que si bien formalmente se pudiera presentar como una fórmula neutra de adaptación a los requerimientos de cambio económico a instancia de cualquiera de las partes, representación de los empresarios o de los trabajadores, material y funcionalmente se aplica a instancias exclusivamente de la representación empresarial.

Como es fácil imaginar, al contraponerse la función adaptativa respecto de la adquisitiva, ésta última en sentido formal se reduce y se limita la inicial función tutelar. Por mucho que la función adaptativa en una perspectiva de conjunto que también pueda leerse en clave de mal menor, que logra el mantenimiento del empleo de los ocupados en un momento dado en una concreta empresa y, por ende, pueda tener esa lectura igualmente de tutela, en lo concreto no cabe la menor duda de que altera la concepción más ortodoxa y tradicional de la función tutelar del convenio colectivo en la clave clásica adquisitiva.

\subsection{Distribución de sacrificios}

A tenor de lo anterior, partiéndose de la aceptación de que en determinadas fases o circunstancias económicas la evolución de los contenidos de los convenios debe ser en clave de deterioro de condiciones desde la perspectiva de los intereses de los trabajadores, ello conduce a que, lo quiera o no, el convenio colectivo debe asumir una función no menos relevante de distribución de sacrificios entre el conjunto de la población asalariada o, dicho con más precisión, del conjunto de los trabajadores incluidos dentro del ámbito de aplicación del convenio colectivo, sea éste sectorial o empresarial.

Más en concreto, esa actuación adaptativa, que comporta deterioro de condiciones, puede producirse de manera lineal, con sacrificios idénticos respecto del total de los empleados incluidos dentro del ámbito de aplicación del convenio colectivo, o bien puede verificarse de manera ponderada o diversificada entre unos y otros, con lo cual el papel que ahora viene a asumir la negociación colectiva no es otro que el de la distribución de sacrificios. Ante situaciones de dificultad económica, la premisa de partida es que necesariamente han de imponerse 
sacrificios por la vía de reducción de rentas y del resto de las condiciones de trabajo, resultado que se le impone inexorablemente desde fuera al proceso de negociación, de modo que al mismo sólo le cabe decidir el reparto subjetivo de los sacrificios a soportar dentro del conjunto de los empleados de la empresa o del sector. La mayor se presenta como indiscutible (la devaluación salarial), al propio tiempo que se le atribuye la menor pero no por ello poco compleja del modo de concretarla en cada concreto grupo de trabajadores. Tarea nada fácil, por cuanto que el sindicato que protagoniza la negociación del convenio debe asumir un rol nada fácil de gestionar junto con la empresa o la asociación empresarial, esa distribución de sacrificios, con la natural incomprensión por parte de los perjudicados.

Desde el punto de vista de la técnica jurídica, el amplio margen de discrecionalidad atribuido a la negociación colectiva en la concreta fijación de las condiciones de trabajo otorga una enorme responsabilidad y una nada agradable función de materialización de la distribución de tales sacrificios. Ese margen resulta especialmente intenso cuando a nuestro juicio el principio de igualdad constitucional sólo se aplica a los poderes públicos y, por ende, no resulta vinculante para la negociación colectiva, si bien es cierto que este criterio no es pacífico en la doctrina y se presenta como confuso en la jurisprudencia constitucional. Expresado a la inversa, el único condicionante a tales efectos de la distribución será el de que en ningún caso tal distribución habrá de efectuarse con resultados que desemboquen en tratamientos discriminatorios. Pero, más allá de ello, el margen de actuación dentro del que se puede mover el convenio colectivo resulta ciertamente amplio. Por ejemplo, no podrá cargar los costes de manera desigual entre trabajadores fijos y temporales (art. 15.6 ET), entre hombres y mujeres (arts. 17 y $28 \mathrm{ET}$ ), la imposibilidad de que el descuelgue de convenio colectivo pueda dar lugar al incumplimiento de las obligaciones establecidas en el convenio relativas a la eliminación de discriminaciones por razones de género o de las que estuviesen previstas, en su caso, en el plan de igualdad aplicable en la empresa (art. $82.3 \mathrm{ET}$ ), etc.; se trata de reglas que resultan deducibles del texto constitucional incluso aunque no se prevea legalmente de manera expresa, si bien se otorga mayor seguridad jurídica y alcance a partir del instante en el que se recoge expresamente en el propio texto del Estatuto de los Trabajadores: el primer ejemplo incorporado en 2001; el segundo desde la primera versión del Estatuto de 1980; el tercero a partir de la reforma de 2011.

Ejemplos típicos de asignación por parte de la norma estatal de ese cometido de distribución de sacrificios puede ser el relativo al establecimiento de los criterios selectivos del personal a perder el empleo 
en caso de despidos colectivos, expreso desde la reforma de 2012: "Mediante convenio colectivo o acuerdo alcanzado durante el período de consultas se podrán establecer prioridades de permanencia a favor de otros colectivos, tales como trabajadores con cargas familiares, mayores de determinada edad o personas con discapacidad" (art. 51.5 ET); habiendo considerado la jurisprudencia constitucional la corrección de establecer como criterio de preferencia para perder el empleo a los trabajadores más próximos a la edad de jubilación (STC 66/2015, de 13 de abril, BOE 22 de mayo). En otras ocasiones no se produce asignación expresa de funciones, pero la negociación colectiva adopta acuerdos que implican distribución de sacrificios y se viene concluyendo que son lícitos; por ejemplo, se entiende que la prohibición de discriminación no impide la aceptación de fórmulas de doble escala salarial en atención al momento del ingreso del trabajador en la empresa, que constituye ejemplo prototípico de distribución de sacrificios articulada a través de la negociación colectiva, si bien con importantes matices y condicionantes por parte de la jurisprudencia constitucional (SSTC 119/2002, de 20 de mayo, BOE de 19 de junio; 27/2004, de 4 de marzo, BOE de 6 de abril; 36/2011, de 28 de marzo, BOE de 28 de abril).

Más aún, en muchas ocasiones se olvida que los procesos de reestructuración empresarial (vía modificaciones de condiciones de trabajo, suspensión de la relación laboral, transmisión de empresa o despidos colectivos por causas económicas), llevan aparejados cambios de lo pactado en los convenios colectivos, o que existen procesos formalmente de consultas con la representación de los trabajadores pero que materialmente comportan auténticos procesos de negociación colectiva, que desembocan en acuerdos de empresa que tienen valor jurídico asimilado al de un estricto convenio colectivo. Esos acuerdos de empresa, como una manifestación hoy en día central de la negociación colectiva, en ese marco de reestructuración de empresas, se convierten hoy en día en un instrumento decisivo en la asunción de esa función de distribución de sacrificios por parte de la negociación colectiva. En ciertas ocasiones, tal distribución la pueden realizar en paralelo a la pervivencia de lo pactado en el convenio colectivo (selección de los trabajadores que soportan la regulación de empleo), si bien en otras ocasiones acometen esa función de reparto de sacrificios impactando sobre lo pactado en el convenio colectivo de aplicación, en la medida en la que el legislador habilite al acuerdo de empresa para alterar lo establecido en el convenio, lo sea por la vía del descuelgue del convenio colectivo o lo sea por medio de reglas de preferencia aplicativa del acuerdo de empresa respecto del convenio colectivo stricto sensu. 


\subsection{Gestión de la segmentación laboral}

A su vez, en ese marco de distribución de sacrificios, emergen escenarios de intensa segmentación del mercado de trabajo, en el sentido de que los sacrificios no se distribuyen de manera homogénea entre todos, sino que unos los soportan con mucha mayor intensidad que otros. En muchas ocasiones ese fenómeno de segmentación del mercado de trabajo deriva de impulsos externos a la negociación colectiva, si bien no por ello la misma deje de tener que enfrentarse a un panorama mucho más complejo, debiendo dar respuesta a los retos de justicia distributiva que inmediatamente provocan los resultados claramente patológicos que manifiestan los fenómenos propios de la segmentación laboral.

Además, tampoco puede ocultarse que, en ciertas ocasiones, ante la indiscutible dificultad que presenta la función adaptativa de reducción de condiciones, emerge como vía de escape o de mal menor el hecho de que acaba siendo la propia negociación colectiva un instrumento de incremento de la segmentación laboral, ya de por sí connatural al desenvolvimiento del mercado de trabajo. Sea cual sea el diagnóstico de las causas desencadenantes del fenómeno de la segmentación, en todo caso, lo que resulta inevitable es que en este nuevo contexto la negociación colectiva se enfrenta como nuevo reto a asumir, la nueva función de gestión de la segmentación laboral, bien en clave de conjurarla o bien con vistas a reducir en la medida de lo posible su expansión. Y, obviamente, tal nueva función de gestión de la segmentación conduce a una nueva lectura de la actuación en el modo de regular sus contenidos los convenios colectivos.

La propia normativa estatal en diversas ocasiones le atribuye a la negociación colectiva facultades importantes de actuación ante determinadas manifestaciones bien conocidas de segmentación laboral. Así, a mero título de ejemplo, son las que se producen entre temporales e indefinido a través de las diversas remisiones que se realizan a la negociación colectiva en esta materia, bien lo sean para determinadas modalidades de contratación, o bien para supuestos de encadenamientos contractuales de diversos trabajadores respecto del mismo puesto (art. 15 ET); las funciones importantes que se le encomiendan en relación con medidas de igualdad por razón de sexo, especialmente a través de los planes de igualdad (art. $85 \mathrm{ET}$ ), incluido todo lo relacionado con la conciliación entre la vida laboral y familiar, en el caso importante del régimen de flexibilidad horaria para atender a responsabilidades familiares (art. $34.8 \mathrm{ET}$ ), con la referencia ya mencionada a la imposibilidad de que los descuelgues puedan afectar a la igualdad de trato (art. $82.3 \mathrm{ET}$ ); teniendo en cuenta también la posible segmentación 
que se puede producir entre trabajadores a tiempo parcial y trabajadores a tiempo completo, con el espacio de actuación que a estos efectos también ostenta la negociación colectiva (art. 12 ET).

\subsection{Instrumento de flexibilidad laboral}

Finalmente, ya como perspectiva de carácter general, las inexorables exigencias de flexibilidad laboral impuestas en el seno de las empresas impactan de manera generalizada y no poco profunda sobre los procesos de negociación colectiva. En efecto, la negociación colectiva no puede actuar a espaldas de una gestión cada vez más flexible de las condiciones de trabajo en las empresas analizado en lo micro, y en el mercado de trabajo visto desde la perspectiva de lo macro. En la medida en que la negociación colectiva mantenga su voluntad de seguir constituyendo una institución central dentro del sistema de relaciones laborales, no puede actuar a espaldas de ese contexto de funcionamiento cada vez más flexible de las relaciones laborales. En suma, en la medida en que quiera actuar en este nuevo contexto e influyendo sobre el mismo, deberá asumir como función adicional la correspondiente a la gestión de la flexibilidad, si no quiere verse abocada a un modelo de flexibilidad unilateral que prescinde por completo de la negociación colectiva y la acaba debilitando hasta límites insospechados.

Importantes ejemplos se pueden encontrar de esta función encomendada a la negociación colectiva. Basta con mencionar con todos los acuerdos de empresa que se pueden alcanzar en el marco de procesos de reestructuración que pueden suponer la implementación de medidas de flexibilidad laboral a través de modificaciones sustancias de condiciones de trabajo (art. $41 \mathrm{ET}$ ), procesos de cambio de titularidad de la empresa (art. 44 ET), suspensiones de contratos y reducciones de jornada (art. $47 \mathrm{ET}$ ), descuelgue de condiciones de trabajo (art. 82.3 ET), incluso de despidos colectivos (art. 51 ET). La propia función de flexibilidad de condiciones presumida que podrían introducir los convenios colectivos en materia de jornada irregular (art. $34 \mathrm{ET}$ ), de clasificación profesional (art. $22 \mathrm{ET}$ ), trabajo a tiempo parcial (art. $12 \mathrm{ET}$ ) y un largo etcétera se podrían enmarcar en esta clave de flexibilidad laboral.

\section{La emergencia de nuevas técnicas jurídicas de relación entre norma estatal y convenio colectivo}


Todas las nuevas funciones así descritas de manera sumaria (adaptativa, distribución de sacrificios, gestión de la segmentación laboral y de flexibilidad), impactan decididamente sobre aspectos institucionales muy variados de la negociación colectiva y, más ampliamente, de terrenos estrictamente ajenos a la negociación colectiva que indiscutiblemente por su intervención fronteriza provocan consecuencias inmediatas sobre los propios convenios colectivos. Dicho de otro modo, todas esas nuevas funciones inciden no exclusivamente sobre los contenidos negociables y las relaciones entre la norma estatal y el convenio colectivo, aunque también influyen perceptiblemente sobre esto último.

En efecto, en su origen, con proyección hasta la actualidad, esas funciones nuevas se producen en muchas ocasiones extramuros de la negociación colectiva. O bien, más importante aún, se verifican intramuros de la negociación colectiva, si bien se articulan sobre cambios en elementos regulativos a los que ya hemos venido haciendo referencia en apartados precedentes, de modo que basta con enumerarlos aquí de conjunto: sucesión normativa entre convenios que permite la reducción de sus estándares por la vía de que el convenio posterior sustituye en su totalidad al anterior sin admisión de mecanismos de garantía de derechos adquiridos, mecanismos de descuelgue convencional que permiten la inaplicación de los estándares pactados colectivamente con precedencia, preferencia aplicativa de los convenios que fijan condiciones menos favorables para los trabajadores, fomento y desarrollo de la negociación colectiva en los procesos de reestructuración empresarial que desembocan en acuerdos de empresa que acaban convirtiéndose en nuevos instrumentos de gestión pactada de la flexibilidad, nueva funcionalidad de la eficacia erga omnes de los convenios colectivos como mecanismo de imposición de lo pactado en clave adaptativa y peyorativa incluyendo a los trabajadores no afiliados o de sindicatos no firmantes dentro de tal vertiente perjudicial, el uso instrumental de la estructura de la negociación colectiva en el marco de la descentralización productiva que habilita para fórmulas diferenciales de condiciones de trabajo, el margen de licitud otorgado a las fórmulas de dobles escalas salariales como mecanismos adaptativos, entre otros.

En la medida en que los procesos de flexibilización y de reducción adaptativa se verifiquen a través de estos canales, el resultado a los efectos que estamos analizando aquí será que ello permitirá mantener los tradicionales principios de relación entre norma estatal y convenio colectivo, de modo que podrá valorarse no sin razón que pervive con solidez el principio de norma mínima. Eso sí, una pervivencia de tal principio que como conclusión a secas y aislada puede resultar de todo 
punto distorsionante de la realidad en la que nos desenvolvemos; distorsionante de la realidad por cuanto que la suplementariedad deja de ser, como en el pasado, el instrumento que permite garantizar férreamente una funcionalidad exclusivamente adquisitiva del convenio colectivo.

En todo caso, más allá de que esas nuevas funciones se puedan materializar sin necesidad de anular el principio de norma mínima o suplementariedad en la relación ley-convenio, lo cierto es que con el paso del tiempo incluso van surgiendo también nuevas técnicas normativas que suponen establecer también nuevas relaciones entre ambas fuentes del ordenamiento laboral que, como tales, acaban debilitando a la relación clásica de norma mínima o suplementariedad.

En esas nuevas relaciones entre la norma estatal y la negociación colectiva se aprecian dos actitudes básicas de parte del legislador frente al rol que a partir de ahora debe desplegar el convenio colectivo frente a las nuevas funciones que se pretende asuma en su conjunto en el sistema de relaciones laborales.

De un lado, una actitud de reforzamiento del protagonismo del convenio colectivo que, si bien se le orienta hacia la asunción de esas nuevas funciones en lo adaptativo al cambio del ciclo económico y de atención a los requerimientos de flexibilidad empresarial, se le hace partícipe de la gestión del cambio y, por tanto, se le invita a gestionar la flexibilidad; esta primera actitud es la que sobre todo da lugar al surgimiento de nuevas reglas de relación entre norma estatal y convenio colectivo, que se adicionan y corrigen en parte a la tradicional propia de la suplementariedad.

De otro lado, una actitud de marcada desconfianza hacia la negociación colectiva, concibiéndola como institución de resistencia y contención de las presiones hacia la introducción de mayores dosis de flexibilidad empresarial, por lo que la intervención legal se orienta hacia el debilitamiento de la negociación colectiva; de la sustracción de la capacidad regulativa a los efectos de que las dosis que se consideran necesarias de flexibilidad se articulen por vías paralelas o alternativas a la negociación colectiva propiamente dicha, para lo cual se establecen reglas que impiden que la negociación colectiva pueda actuar como obstáculo a los objetivos y fines pretendidos por determinadas reformas laborales acometidas desde la norma estatal.

Ambas actitudes, como puede fácilmente intuirse, de principio se presentan en clave antagónica, por cuanto que la primera conduce a una mayor centralidad y protagonismo de la negociación colectiva, mientras que la segunda se materializa en una restricción del margen de actuación de la propia negociación colectiva. No obstante, en nuestro vigente 
ordenamiento jurídico se puede percibir la presencia al propio tiempo de manifestaciones de una y otra actitud, bien lo sea porque tienen su origen en reformas legislativas de momentos diferentes con opuestas concepciones de la negociación colectiva pero que conviven en la regulación actual, o bien porque se interviene con actitudes diferenciadas según la materia objeto de regulación y del grado de influencia material que se le desee otorgar a la negociación colectiva.

Si nos centramos en primer lugar, en la primera de las actitudes mencionadas, de reforzamiento del protagonismo del convenio colectivo, advertimos a su vez formas muy variadas de establecer las relaciones entre la Ley y el convenio colectivo, según la intensidad de la intervención convencional que se desee introducir. Así, a título meramente ejemplificativo, y sin poder con ello llegar a proporcionar una ponderación de conjunto del proceso acumulativo aluvional al que ya nos hemos venido refiriendo, cabe enumerar el siguiente nuevo tipo de relaciones entre Ley y convenio colectivo, incorporadas con sucesivas reformas.

Haciendo una mención secuencial en atención a las primeras manifestaciones que fueron surgiendo, mencionaríamos en primer lugar aquellas previsiones legales que facultan al convenio colectivo para establecer un régimen más limitativo de derechos individuales: la ley de principio otorga un derecho subjetivo al trabajador, pero sucesivamente permite que sea corregido o limitado por el convenio colectivo. Así, por ejemplo, en un panorama de gestión negocial de los excedentes de empleo, lo primero que hizo la legislación laboral fue pasar de un principio general de voluntariedad de la jubilación del trabajador a un modelo en el que se permitía al convenio colectivo sustraer esa libre voluntad a cada trabajador individual para regular fórmulas de jubilación obligatoria (disp.. adicional $5^{\mathrm{a}}$ ET en su versión de 1980), medida que como tal fue considerada correcta por parte de la jurisprudencia constitucional del momento (por todas, STC 58/1985, de 30 de abril, BOE 5 de junio). Si bien, posteriormente, el legislador, por motivos diversos, cambie de orientación en esta concreta materia, ha sido una larga práctica convencional la que se ha desarrollado en este terreno, se ha extendido a otras vertientes de la gestión de las regulaciones de empleo, incluso ha provocado que establecida la prohibición posterior en esta materia, la negociación colectiva busque fórmulas alternativas que produzcan resultados semejantes. Dentro de este grupo cabría mencionar también las reglas sobre conversión de las horas extraordinarias de voluntarias en forzosas a través de la negociación colectiva (art. 35.4 ET), medida de larga tradición entre nosotros.

La segunda de las fórmulas, una de las más conocidas y 
extendidas, será la correspondiente a la aparición de la relación de supletoriedad o de subsidiariedad (según denominación alternativa por parte de unos u otros autores), que comporta una regulación en la norma estatal, que puede ser alterada, tanto en clave ampliatoria como reductiva de derechos de los trabajadores, visto en clave opuesta de flexibilidad empresarial. Ejemplo paradigmático de ello será la regulación general de la duración del período de prueba contemplada en el Estatuto de los Trabajadores, con fijación de duraciones que desde la reforma de 1994 juegan como indisponibles para el contrato de trabajo pero alterable en cualquier sentido por el convenio colectivo (art. 14.1 ET). En este mismo grupo se podrían mencionar las reglas relativas a la fijación, también desde los inicios de la década de los noventa del siglo pasado, del establecimiento de distribución de manera irregular de la jornada a lo largo del año, con un porcentaje referencia en la ley pero plenamente alterable por la negociación colectiva (art. 34.2 ET).

La tercera de las fórmulas, como una cierta variante de lo anterior, si bien más limitativa, sería la técnica de fijación de topes máximos y mínimos por parte de la norma estatal, que a modo de técnica horquilla, permite al convenio colectivo alterar la previsión legal, si bien lo sea dentro de determinados límites. Ejemplo paradigmático de ello será la regulación de la duración de algunos contratos temporales causales así como de los contratos formativos, con límites mínimos y máximos de duración dentro de los que se permite que se mueva la negociación colectiva: contrato para obra o servicio determinado (art. 15.1.a ET), contrato eventual (art. 15.1.b ET), contrato de trabajo prácticas (art. 11.1.b), contrato para la formación y el aprendizaje (art. 11.2.b ET). En los mismos términos juega la regulación actual del porcentaje de las horas complementarias a fijar vía contrato de trabajo, con un límite que puede ser alterado por el convenio colectivo pero con un tope, de modo que se juega del mismo modo entre una horquilla mínima y máxima (art. 12.5.c ET).

Comoquiera que las tipificaciones teóricas a veces se presenten como simplificadoras y formales en exceso, en ocasiones no encajan del todo con lo que se pretende exponer. Me refiero al hecho de que desde cierta perspectiva estos ejemplos también se podrían citar como exponentes de la segunda de las actitudes del legislador frente a la negociación colectiva. En efecto, en tales casos lo que se hace es introducir un estándar de tutela del trabajador en la norma estatal, llamando a una posible intervención de la negociación colectiva, pero que siempre y en todo caso debe tener un alcance en la dirección de provocar un incremento de los márgenes de flexibilidad a introducir por el convenio colectivo, nunca en la dirección opuesta de limitar o contender 
tales márgenes de flexibilidad.

La cuarta de las fórmulas, empleado sobre todo a resultas de reformas introducidas en 2013, sería aquella conforme a la cual la norma estatal permite al convenio colectivo establecer reglas siempre y sólo en la dirección de incrementar dosis de flexibilidad a favor de la empresa; en este caso el legislador estatal parte de fijar un umbral de flexibilidad, pero con posibilidad de que la negociación colectiva lo intensifique. En la práctica despliega una funcionalidad muy similar al supuesto precedente de la técnica horquilla, pues si bien formalmente no existe tope a ese incremento de flexibilidad por propia naturaleza de la institución sí que existe. Ejemplo en este caso sería de nuevo la materia relativa a la fijación del número de horas complementarias en el trabajo a tiempo parcial, donde a la negociación colectiva se le impide reducir el número de horas previstas legalmente (art. 12.5.c ET); o bien, la regulación del preaviso de la realización de horas complementarias, en cuyo caso el convenio colectivo sólo puede reducir el duración del preaviso (art. 12.5.d ET); se entiende con un límite por naturaleza en la medida en que, aunque no se diga expresamente en la norma legal, se presupone que no puede eliminar la existencia del preaviso por muy reducido que sea éste.

\section{La emergencia de técnicas prohibitivas o alternativas a lo negociable}

Como indicamos en el apartado precedente, al margen de las relaciones directas entre Ley y convenio colectivo, aparecen unas relaciones indirectas o incluso una negación de diálogo entre ambas fuentes, que serían las expresivas de la otra actitud de desconfianza frente a la negociación colectiva que conducen a impedirle actuar o a la búsqueda de canales alternativos a la flexibilidad gestionada al margen de la negociación colectiva.

La expresión más evidente y al propio tiempo la más cruda se produce allí donde la normativa estatal impide o le prohíbe intervenir al convenio colectivo.

No cabe la menor duda de que desde sus orígenes, por razón de su naturaleza contractual o de toma en consideración de estrictos intereses privados, se contemplaban multitud de aspectos regulados por el ordenamiento estatal de imposible intervención por parte de la negociación colectiva. Al tratarse de materias de afectación a intereses generales de la comunidad, intereses públicos o de incidencia sobre intereses particulares pero de afectación a terceros ajenos al ámbito de aplicación del convenio colectivo, se establecía desde sus inicios una 
amplia prohibición de intervención, a cuyo efecto se construye la noción de "orden público laboral", que es la que fundamenta los límites intrínsecos de lo pactable colectivamente. Así, ejemplo prototípico será, desde la primera versión del ET de 1980, cuando se establezca que todas las cargas fiscales y de Seguridad Social a cargo del trabajador serán satisfechas por el mismo, "siendo nulo todo pacto en contrario" (art. 26.4 ET), que de manera pacífica se interpreta refiere tanto al pacto individual como al convenio colectivo. Incluso a ciertos efectos, la técnica de la reserva normativa viene a desplegar un resultado similar; por ejemplo, regla pocas veces tomada en consideración, cuando se dispone que las exclusiones, reservas y preferencias para ser contratados libremente deben establecerse por ley (art. 17.2 ET).

Ahora bien, la novedad que aparece en tiempos recientes es que, aunque por medio de una técnica de relación tan tradicional como es la prohibición regulativa o la reserva normativa, ahora se extienden este tipo de límites o impedimentos pero en la actualidad en el marco de la nuevas funcionalidades atribuidas al ordenamiento laboral, ajenas a la lógica de la tutela del trabajador. Ahora el legislador establece un marco que considera imprescindible de flexibilidad a favor del empleador, que, por tanto, no puede ser corregido o eliminado por parte de la negociación colectiva. Visto desde otra perspectiva, ahora lo que hace el legislador es canalizar la flexibilidad a través de procedimientos diversos, que tienen en común el resultar inexpugnables por la negociación colectiva. Se sustrae a la negociación colectiva el protagonismo y se sitúa en otra sede. En unos casos, lo que hace el legislador es reconducir la flexibilidad a la autonomía individual de la voluntad, de modo que es en sede del pacto individual, más o menos real desde la perspectiva material, donde se fija el margen de flexibilidad, pero sin que en esa materia pueda actuar la negociación colectiva. Por ejemplo, tal sucede cuando el legislador abre paso a los pactos de polivalencia funcional vía contrato de trabajo, que incrementan las dosis de flexibilidad empresarial sin que los mismos puedan ser contradichos por vía del sistema de clasificación profesional establecido en la negociación colectiva (art. 22.4 ET).

En otros casos, lo que hace la norma estatal es dirigirse directamente a las facultades unilaterales del empleador, reconociendo al mismo determinadas dosis de flexibilidad laboral, que como tales no pueden ser alteradas por la negociación colectiva. Por ejemplo, así sucede también con el vigente régimen de movilidad funcional otorgado a favor del empleador, que en los términos en los que se encuentra regulado legalmente se mantienen sin posibilidad de reducción por parte del convenio colectivo, ni siquiera admitiendo su limitación una vez más por la vía del sistema de clasificación profesional que pueda establecerse a 
través del convenio colectivo de aplicación (art. 39 ET).

Tampoco dejan de aparecer ampliaciones de las materias para las que de forma expresa o implícita se contemplan reglas prohibitivas de intervención por parte de la negociación colectiva. De este modo, no se desea que la negociación colectiva tenga ningún impacto, por cuanto que se desea que este provenga directamente de la norma estatal y, en particular, que el convenio colectivo no pueda minorar ni impedir ese impacto legal. Ejemplo típico de ampliación de la relación de supuestos de prohibición expresa hoy en día sería la imposibilidad de establecimiento por parte de los convenios colectivos de mecanismos de jubilación obligatoria, con vistas a que los convenios colectivos no puedan reducir el efecto deseado de prolongación de la edad de jubilación: "Se entenderán nulas y sin efecto las cláusulas de los convenios colectivos que posibiliten la extinción del contrato de trabajo por el cumplimiento por parte del trabajador de la edad ordinaria de jubilación fijada en la normativa de Seguridad Social, cualquiera que sea la extensión y alcance de dichas cláusulas" (disp. adic. 10ª ET, en su versión de 2012). Ejemplo de prohibición implícita sería la previsión del período de prueba de un año en los contratos de trabajo indefinidos para empresas de menos de 50 trabajadores, para los que no se permite que el convenio colectivo altere la duración de dicho período de prueba fijado por la norma estatal, sin permitir que los convenios colectivos puedan alterar su duración, siendo por contraste esa posibilidad amplísima para el régimen general del período de prueba para el resto de los contratos (art. 4 Ley 3/2012, de 6 de julio, BOE 7 de julio). En la misma línea se sitúa la preferencia aplicativa del convenio de empresa, que por su carácter indisponible no permite su alteración por parte de la negociación colectiva sectorial, ni siquiera por parte de los acuerdos interprofesionales (art. 84.2 ET). Igualmente sucede con la actual regulación del procedimiento de descuelgue del convenio colectivo, donde a partir de la reforma laboral de 2012 , de una parte se rompe con los mecanismos precedentes donde se presentaba una decisiva remisión a la negociación colectiva para que fuera ésta quien articulara el procedimiento más adecuado de inaplicación convencional a juicio de las partes, al mismo tiempo que la actual regulación también rompe con la exigencia de que el descuelgue se produzca en todo caso por vía pactada dado que abre paso a un posible arbitraje a instancia unilateral de la representación empresarial sin compromiso arbitral previo por parte de la representación de los trabajadores e incluso de manera oculta habilita para un descuelgue ficticiamente pactado con unas comisiones 'ad hoc' de difícil control en cuanto a su efectiva legitimidad democrática (art. 82.3 ET).

Conviene también advertir, para cerrar el panorama, que, en 
otras ocasiones, la intervención legislativa es más imprecisa u oculta, pues sin llegar a utilizar la técnica prohibitiva, lo que hace es proceder a establecer una regulación desde la ley autosuficiente. Se trata de una autosuficiencia que, de un lado, no contempla, como en otras ocasiones, reiteradas remisiones a la intervención convencional como ha llevado a cabo con reformas en las que era más propenso a la colaboración entre ambas fuentes, al propio tiempo que, de otro lado, la precisión legal regulativa llega a tal detalle que concibe perfectamente funcional la aplicabilidad plena de la institución objeto de regulación sin intervención de la negociación colectiva, ni siquiera en clave de complementariedad. Formalmente no establece un mecanismo de reserva de ley, pero materialmente despliega un resultado prácticamente idéntico. Ahora lo que se contempla es la introducción de un nuevo régimen legal, que para su aplicación práctica no precisa de la intermediación de la negociación colectiva, por cuanto que la regulación legal se presenta como autosuficiente y no precisa de la intervención de la negociación colectiva para su efectividad. Incluso a veces, presentando la apariencia de la necesidad de una adaptación de los convenios colectivos a los nuevos postulados legales, se incorpora una regulación que hace innecesaria dicha adaptación para que la reforma tenga impacto inmediato sobre la realidad laboral y empresarial. Cabe mencionar al efecto como ejemplo paradigmático la definitiva sustitución del modelo de clasificación profesional sobre la base de categorías por el más amplio de grupos profesionales, incluyéndose un plazo perentorio de un año para que los convenios colectivos procediesen a resultas de la reforma de 2012 a la renovación del sistema de clasificación profesional en aquellos que aún no tengan incorporados el criterio de los grupos profesionales (art. 22 ET). Otro ejemplo, que no requiere de mayor detalle para no ser redundantes, es el relativo al procedimiento de descuelgue convencional, especialmente a partir de la reforma de 2012: mientras que con precedencia todo el mecanismo de descuelgue quedaba al albur de lo que los diversos convenios estableciesen respecto del procedimiento de materialización del mismo, ahora la norma estatutaria es completa y perfecta, sin precisar su desarrollo ni aval por parte de la negociación colectiva en cada uno de los ámbitos y niveles (art. 82.3 ET).

\section{Conclusión}

Contemplado en su conjunto, sin poder ponderar al detalle la intensidad de los cambios que se están produciendo en el marco regulador de la negociación colectiva $y$, en particular, en las nuevas 
técnicas de relación ley-convenio ni de valorar su intensidad, lo que es evidente es que las nuevas fórmulas conviven con las tradicionales, que las funciones más clásicas intentan pervivir junto a las emergentes. A vista de pájaro puede considerarse que el carácter protector y de tutela de la posición jurídica del trabajador prevalece como decisivo dentro de las funciones del convenio colectivo; por tanto, resulta igualmente indiscutible que permanece como central todavía el criterio de la suplementariedad y de la pervivencia de la norma mínima. Pero, al propio tiempo, ello no desmerece de la trascendencia acumulativa de las nuevas fórmulas $\mathrm{y}$, por ende, de la progresiva intensificación de las relaciones propiciadoras de una intervención del convenio colectivo en clave de gestión de la flexibilidad empresarial.

$\mathrm{Al}$ propio tiempo, sobrevuela la hipótesis de opciones alternativas de política del Derecho donde, ya no sólo se pretenda provocar un cambio de orientación más o menos profundo en la funcionalidad de la negociación colectiva, ahora en clave esencialmente adaptativa y de gestión de la flexibilidad, sino que lo que se pretenda sea que esa finalidad adaptativa y de flexibilidad se materialice en el sistema de relaciones laborales al margen o de espaldas a la propia negociación colectiva. Lo primero conduciría a la pervivencia de la relevancia e influencia de la negociación colectiva en el devenir de las relaciones laborales, mientras que lo segundo abocaría su pérdida de protagonismo y de marginalidad. A lo postre lo que está en juego es esa funcionalidad política o de gobierno del sistema de relaciones laborales que le corresponde a la negociación colectiva como expresión por excelencia del principio constitucional de autonomía colectiva.

Hasta donde pueda evolucionar el modelo de futuro es difícil adivinarlo, por cuanto que las reformas que se puedan avecinar es difícil intuirlas y menos aún calibrarlas. En todo caso sí que puede considerarse ya como pacífico que estos cambios funcionales y de técnicas jurídicas se asientan con solidez como seña de identidad del actual modelo de relaciones laborales, adquiriendo carácter estructural dentro de nuestro sistema de negociación colectiva y, en definitiva, obligan, por ende, a un nada fácil equilibrio tanto del conjunto de las funciones de la negociación colectiva como de las técnicas de relación ley-convenio que le acompañan.

\section{Bibliografía}

Alarcón Caracuel, M. R. (1983). "Un concepto clásico de la relación entre Ley y convenio colectivo", en AA. VV. (F. Durán López coord.), "Las 
relaciones laborales y la reorganización del sistema productivo", Publicaciones del Monte de Piedad y Caja de Ahorros de Córdoba, Córdoba.

AA.VV. (1998). "Las relaciones Ley-convenio colectivo", en E. Rojo Torrecilla (coord.), Las reformas laborales de 1994 y 1997, Ed. Marcial Pons, Barcelona.

Giugni, G. (1989). "La funzione giuridica del contratto collettivo di lavoro", en Lavoro, legge e contratto, Bolonia.

Rivero Lamas, J. (1998). "Estructura y funciones de la negociación colectiva tras la reforma laboral de 1997”, Revista Española de Derecho del Trabajo $\mathrm{n}^{\mathrm{o}} 89$.

Valdés Dal-Ré, F. (2012). "La reforma de la negociación colectiva: la irrazonable exacerbación de la función de gestión" Relaciones Laborales $\mathrm{n}^{\circ} 23 / 24$.

Vardaro, G. (1983). "Il mutamento della funzione del contratto collettivo" Giornale di Diritto del Lavoro de delle Relazioni Industrialli.

Villavicencio Ríos, A. (2005) "La redefinición de las funciones y los modelos de negociación colectiva en los albores del siglo XXI" Ius et Veritas (Universidad Pontificia Católica del Perú) vol. 15 nº 31 (2005); también publicado en Relaciones Laborales (Uruguay) $\mathrm{n}^{\circ} 8$. 